\title{
ANALYSIS OF THE INITIAL IMPERFECTIONS EFFECT ON THE THIN-WALLED COLD-FORMED COMPRESSED STEEL MEMBERS
}

The paper deals with the influence of initial imperfections and presents fundamental information about experimental and theoretical-numerical research to determinate the load-carrying capacity of thin-walled cold-formed compressed steel members. The investigated members had closed cross-sections made of homogeneous material. The theoretical-numerical analysis in this paper is oriented on the investigation and modeling of initial imperfections effects, caused by production process, on the load-carrying capacities of mentioned members, while the experimental investigation is to verify the theoretical results and to investigate the behavior of mentioned members during the loading process.

Key words: initial imperfections, thin-walled cold-formed profiles, steel structure, load-carrying capacity, plasticity, modeling, experiment

\section{Introduction}

Theory and design development of steel thin-walled cold-formed members and profiles creates a certain knowledge base for their practical application in the civil engineering. However, this fact does not mean that all the complicated and challenging processes of their behavior, during the strain, transformation and failure are sufficiently investigated. From the material and geometric point of view, the thin-walled cold-formed profiles have specific specialties, which must be responsibly taken into account in their design [1]. From this aspect, the local stability requirements related to unfavorable buckling effects of their compressed parts are very significant. Favorable effects, related to membrane stresses and post-critical behavior are also important. Different calculation procedures in different standards (STN 73 1402:1988, STN EN 1993-1-3: 2006), reciprocal comparison of the results and their comparison to with existing experimental results indicate the need for further theoretical and experimental investigation of the post-critical behavior and elastic-plastic resistance of thin-walled profiles.

\section{Description of the testing members}

In general, the experimental research program included 18 thinwalled cold-formed testing members with closed cross-sections. The testing members were divided into two cross-sectional groups:

- Group A: with square cross-sections,

- Group B: with rectangular cross-sections; see Fig. 1.

Different dimensions of closed cross-sections and tested members were chosen to reflect the post-critical behavior of their several thin webs during strain, transformation and failure processes.

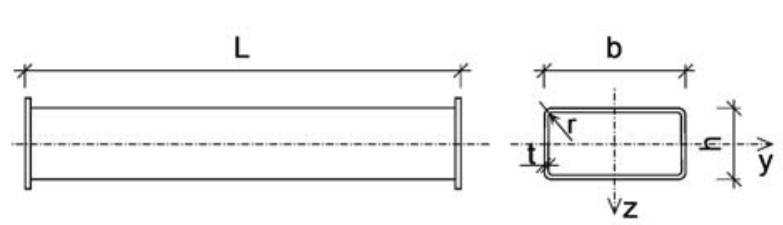

Fig. 1 Scheme of testing members, Group B

The obtained results are very extensive; therefore the paper deals only with group B, Tab. 1, Tab. 2.

Geometrical dimensions of the designed

Tab. 1.

members, group B

\begin{tabular}{|c|c|c|c|c|c|c|c|c|}
\hline \multicolumn{3}{|c|}{ Testing members } & \multicolumn{5}{|c|}{ Geometrical dimensions [mm] } & Steel \\
\hline \multicolumn{2}{|c|}{$\begin{array}{l}\text { Cross-sectiona } \\
\text { group }\end{array}$} & Marking & b & $\mathrm{h}$ & $\mathrm{t}$ & $\mathrm{r}$ & $\mathrm{L}$ & \multirow{4}{*}{ S235 } \\
\hline \multirow{3}{*}{ B } & 1 & $\begin{array}{c}\text { B11, B12, } \\
\text { B13 }\end{array}$ & 150 & 100 & \multirow{3}{*}{2} & \multirow{3}{*}{3} & 450 & \\
\hline & 2 & $\begin{array}{c}\text { B21, B22, } \\
\text { B23 }\end{array}$ & 200 & 100 & & & 650 & \\
\hline & 3 & $\begin{array}{c}\text { B31, B32, } \\
\text { B33 }\end{array}$ & 200 & 150 & & & 600 & \\
\hline
\end{tabular}

In the terms of local-stability classification, the webs of individual members are thin-walled at the compressive strain. The members' lengths were designed from the global stability point of view, in order to decide of the members' local (cross-sectional) resistance.

\footnotetext{
* Mohamad Al Ali, Michal Tomko, Ivo Demjan, Vincent Kvocak

Technical University, Faculty of Civil Engineering, Institute of Structural Engineering, Kosice, Slovakia, E-mail: mohamad.alali@tuke.sk
} 
Basic geometrical characteristics of the designed testing members, group B

Tab. 2

\begin{tabular}{|c|c|c|c|c|c|c|c|c|c|}
\hline \multirow{2}{*}{\multicolumn{2}{|c|}{ Cross-sectional group }} & \multicolumn{4}{|c|}{ STN EN 1993-1-3:2006 } & \multicolumn{4}{|c|}{ STN 73 1402:1988 } \\
\hline & & \multirow{2}{*}{$\begin{array}{c}\frac{\beta_{b}}{73.12} \\
73\end{array}$} & \multirow{2}{*}{$\begin{array}{c}\beta_{h} \\
48.12\end{array}$} & \multirow{2}{*}{$\frac{\lambda_{y}}{10.70}$} & \multirow{2}{*}{$\frac{\lambda_{z}}{7.87}$} & \multirow{2}{*}{$\frac{\beta_{b}}{71.00}$} & \multirow{2}{*}{$\frac{\beta_{h}}{46.00}$} & \multirow{2}{*}{$\begin{array}{c}\lambda_{y} \\
10.74\end{array}$} & \multirow{2}{*}{$\begin{array}{c}\lambda_{z} \\
7.89\end{array}$} \\
\hline B & 1 & & & & & & & & \\
\hline & 2 & 98.12 & 48.12 & 15.01 & 8.84 & 96.00 & 46.00 & 15.05 & 8.85 \\
\hline & 3 & 98.12 & 73.12 & 9.58 & 7.71 & 96.00 & 71.00 & 9.60 & 7.72 \\
\hline
\end{tabular}

All testing members were made out from steel sheets with nominal thickness $2 \mathrm{~mm}$ (steel S235). Three material pieces were taken from each used steel sheet to make normative shaped testing specimens. The testing specimens underwent a tension tests to find out the stress-strain diagrams and the actual material characteristics of applied steels.

Detailed dimension measuring of the testing members was done before the loading tests, in order to achieve consistent evaluation and analyses of the experimental knowledge and results. The dimensions of cross-sections: width $b$, height $h$, and thickness $t$, were measured at the top, middle and bottom of each member. The radius $r$ was measured at each curved corner and the length $L$ was measured at each member's side. The average values of the measured dimensions were considered as actual; see Tab. 3 .

Average dimensions values and actual

Tab. 3 . material characteristics

\begin{tabular}{|c|c|c|c|c|c|c|c|}
\hline \multirow{2}{*}{ Member } & $b$ & $h$ & $t$ & $r$ & $L$ & $f_{y}$ & $f_{u}$ \\
\cline { 2 - 7 } & \multicolumn{5}{|c|}{$[\mathrm{mm}]$} \\
\hline B21 & 207.93 & 103.08 & 2.12 & 3.0 & 650.00 & 242.33 & 360.00 \\
\hline B22 & 207.47 & 103.18 & 2.10 & 3.0 & 649.88 & 242.33 & 360.00 \\
\hline B23 & 207.35 & 102.62 & 2.16 & 3.0 & 649.25 & 242.33 & 360.00 \\
\hline
\end{tabular}

\section{Testing methodology and limit loads}

During the consecutive programmed loading of the tested members, the strains $\varepsilon$ were measured using resistive strain gauges in the middle cross-sections and the deflections (buckling) of the webs $w$ were measured using inductive sensors at different places, according to the members lengths. The resistive gauges and inductive sensors were connected to the computer for direct evaluation. The loading process of each member was regulated close to its real behavior, measured strains $\varepsilon$ and deflections $w$. The test continued up to the total failure defined by the beginning of continuous increasing of strains $\varepsilon$ and deflections of the webs $w$.

According to the research targets, the initial buckling shapes of all tested members' webs were measured on previously drawn raster, by means of inductive sensors before testing start. The final buckling shapes, after test finishing were also obtained [2].

Taking into account real-measured dimensions and yield stresses, the limit loads of all tested members were calculated according to relevant standards [3 - 5]. Theoretical and experimental limit loads are presented in Tab. 4. It is evident from Table 4 that the experimental limit loads are smaller than the expected theoretical values. This serious fact may incur in consequence of the unfavorable development of initial imperfections. This unfavorable influence of the initial imperfections is analyzed in detail in the following section.

In Table 4 the following notation was used:

$N_{p l}$ - the local plastic limit load of full cross-section, defined by attaining the yield stress fy,

$N_{u l e l}$ - the local (post-critical) elastic limit load of effective crosssection, defined by attaining the yield stress $f_{y}$,

The above mentioned theoretical limit loads with indices (STN) were calculated according to the Slovak technical standard STN 73 1402:1988, considering chapter 6/6.8.1 of the Slovak technical standard STN 73 1401:1998. Theoretical limit loads with indices (EN) were calculated according to the European standard STN EN 1993-1-3:2006, considering chapters 4/4.1 - 4/4.4 of the standard STN EN 1993-1-5:2006 and chapter 6/6.3.1 of the standard STN EN 1993-1-1:2006.

Theoretical and experimental limit loads

Tab. 4

\begin{tabular}{|c|c|c|c|c|c|c|c|c|c|}
\hline \multirow{2}{*}{ Member } & $N_{p l, S T N}$ & $N_{p l, E N}$ & $N_{\text {ulel, }, \text { STN }}$ & $N_{\text {ulel, }, E N}$ & $N_{u, y, S T N}$ & $N_{u, y, E N}$ & $N_{u, z, S T N}$ & $N_{u, z, E N}$ & $N_{u, \exp }$ \\
\hline & \multicolumn{9}{|c|}{$[\mathrm{kN}]$} \\
\hline B21 & 312.08 & 309.4 & 229.3 & 194.45 & 229.3 & 194.45 & 229.3 & 194.45 & 171.15 \\
\hline B22 & 309.28 & 306.62 & 226.3 & 191.76 & 226.3 & 191.76 & 226.3 & 191.76 & 173.27 \\
\hline B23 & 316.63 & 313.93 & 234.79 & 200.55 & 234.79 & 200.55 & 234.79 & 200.55 & 164.77 \\
\hline
\end{tabular}




\section{Calculation models and the experiment simulation}

Calculation models of the testing members, described in Tab 3 , were created using software based on FEM - ANSYS [6, 7 and 8]. The target of the FEM analysis was to obtain more accurate data about the post-critical behavior of the mentioned members, to determine their limit loads and to compare them with the experimental results. In this paper, the obtained analysis results are compared to the theoretical and experimental limit loads of the actual testing members B21, B22 and B23.

The volume shell elements SOLSH190 were applied to create the calculation models. The finite element SOLSH190 is usually used for the simulation of shell structures with wide range of thicknesses (from thin to medium thickness). This element, with eight connecting nodes, has three degrees of freedom at each node. The element may be used to solve the geometrical and physical nonlinear problems. This type may be also used for the composite multilayer modeling (up to 250 different material's layers).

The modeling was carried out with considering the initial imperfections. Fig. 2 illustrates the arrangement of the tests with some views on the member after the test finishing. The values of the measured initial imperfections in individual grid points were considered in the 3D models [2].

Each of the 3D calculation models (B21, B22 and B23) contains 4182 nods and 4100 shell elements. Boundary conditions of the modeled, axially compressed members were defined by the two-sided hinged connections.

Two types of calculation models were used to verify the initial imperfections effect:

- With the consideration of the webs' initial deviation,

- Without the consideration of the webs' initial deviation.
Elastic-plastic material with hardening was considered with the use of the plastic zones method. This material is characterized by a bilinear approximation of the strain-stress diagram of steel with yield stress $f_{y}=242.33 \mathrm{MPa}$ and hardening modulus $E_{\text {hard }}=2800$ MPa [2].

The modeling of testing members was carried out according to above mentioned description. Fig. 3 illustrates the 3D model with generated grid for initial imperfections defining $(\mathrm{a}-\mathrm{b})$ and finite element mesh of volume shell elements SOLSH190 (c).

The analysis was carried out with sequentially increasing the applied load until the first appearance of plastic zones locations. The applied load was transformed to the middle-plane of the shell elements. The model was analyzed using the geometrical and physical non-linear calculation.

\section{Results and their analysis}

The final webs' buckling shapes in topographical form, together with the equivalent elastic strain of the modeled member B22 is presented in Fig. 4. Fig. 5 illustrates the equivalent stress and plastic strain of the mentioned member.

The comparison of the several limit loads of tested members B21, B22 and B23, obtained by the theoretical, FEM simulation and experimental investigation are illustrated in Fig. 6.

From Fig. 6 is evident that the experimental limit loads of individual tested members are smaller than the limit loads obtained by relevant standards. Fig. 6 also presents the influence of initial imperfections through the process of the 3D FEM simulations.
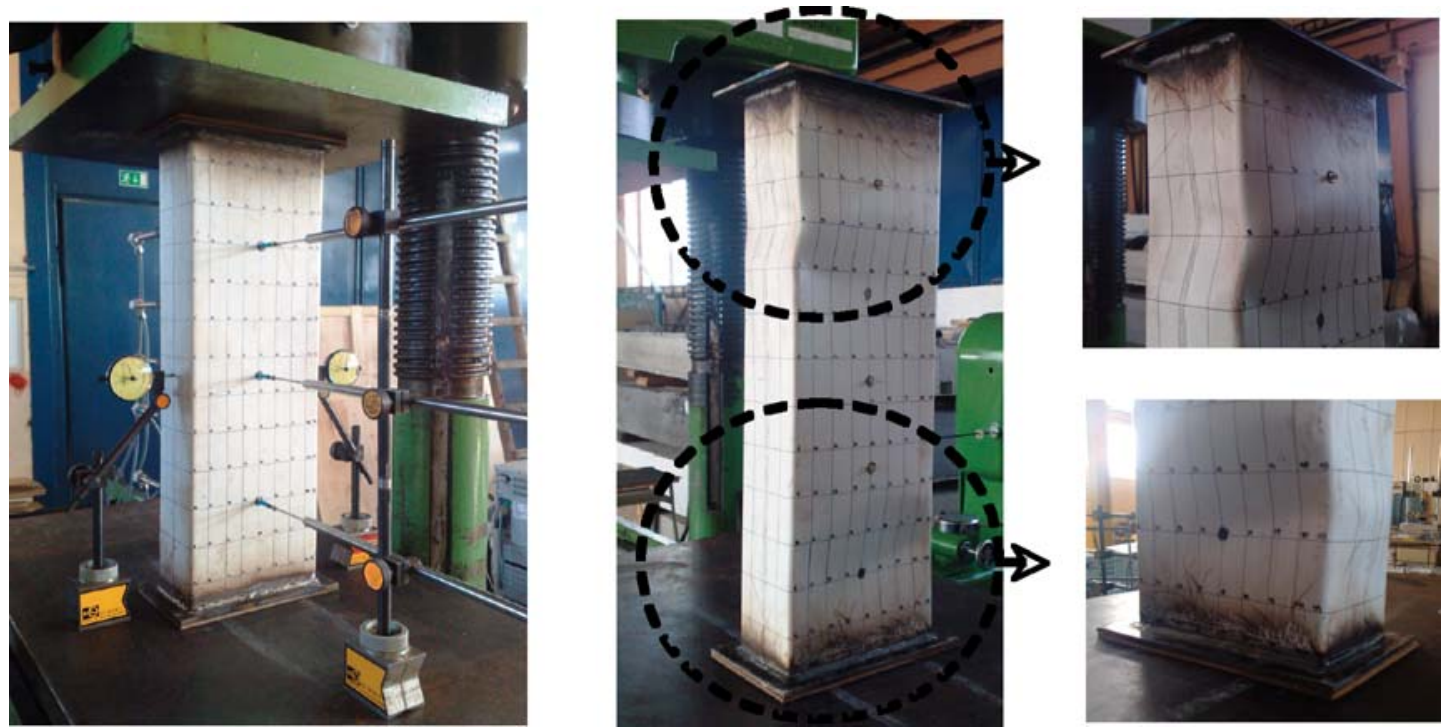

Fig. 2 Arrangement of the tests and the member failure shape

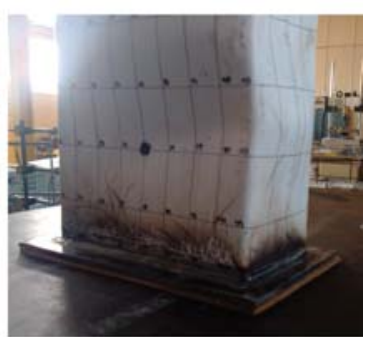




\section{COMMNICOIIONS}
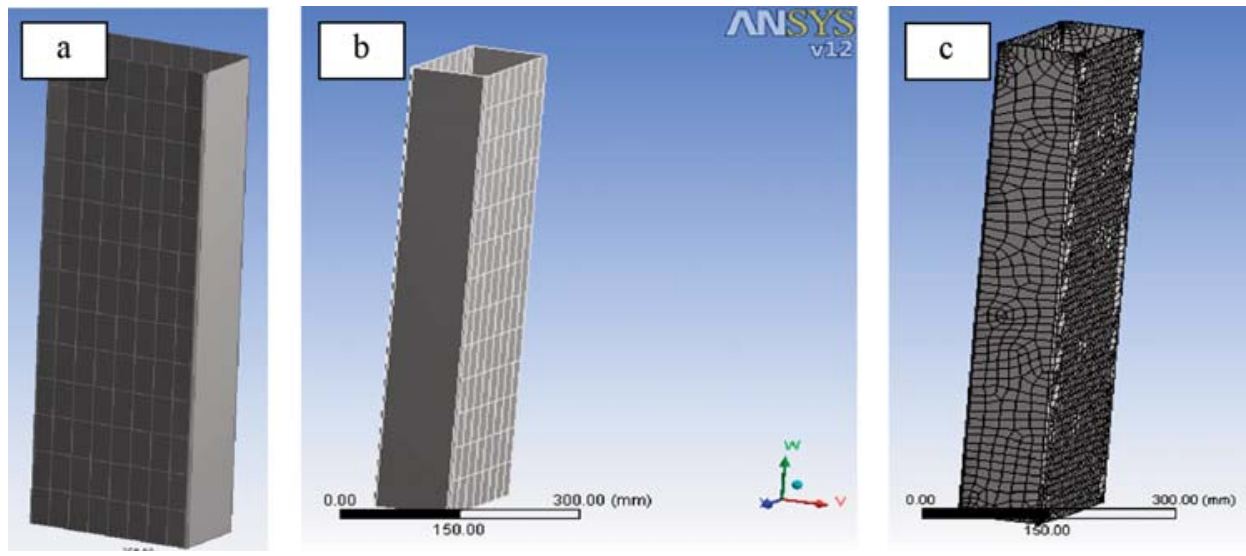

Fig. 3 Configuration of the calculation model, member B22
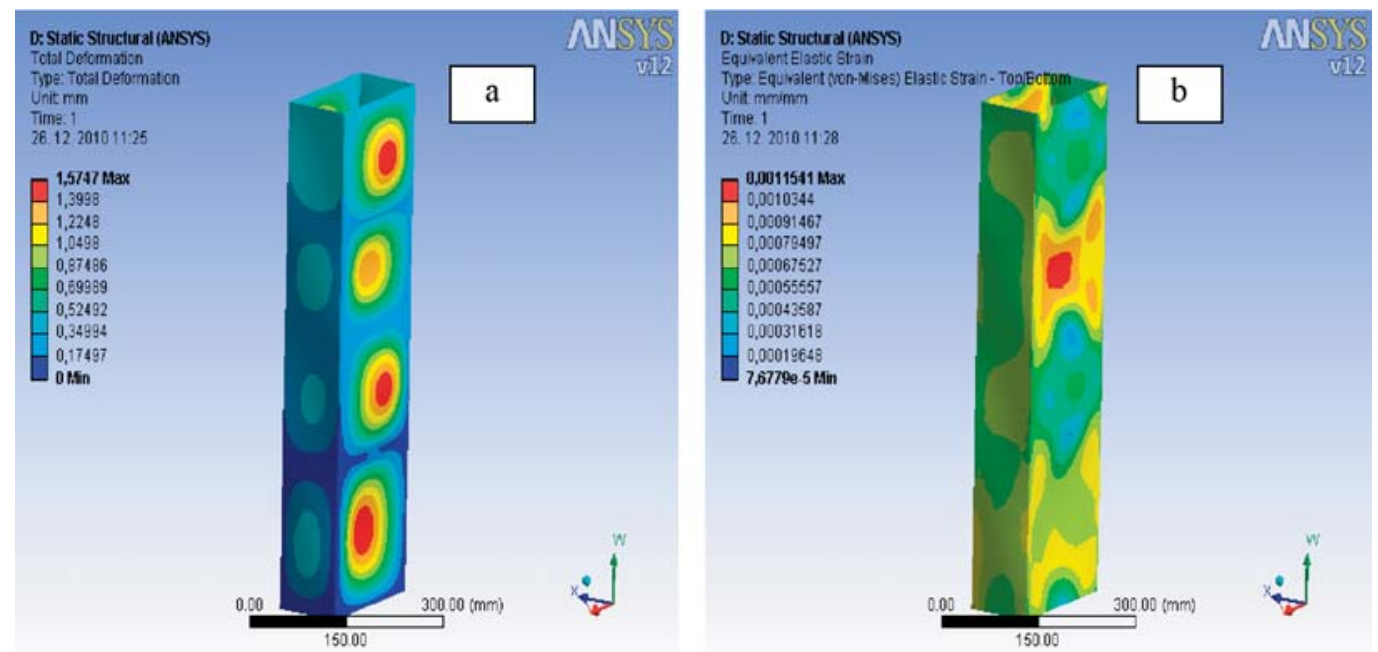

Fig. 4 Final deformation (a) and equivalent elastic strain (b), member B22
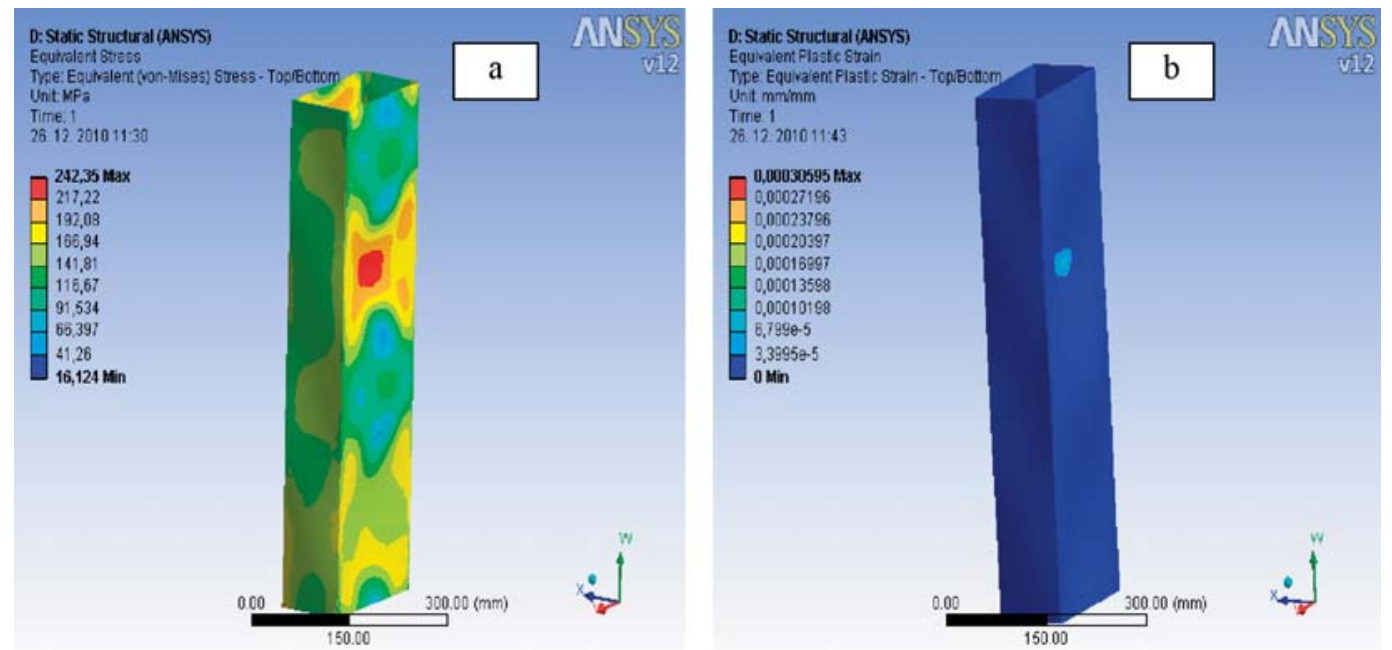

Fig. 5 Equivalent stress (a) and equivalent plastic strain (b), member B22 


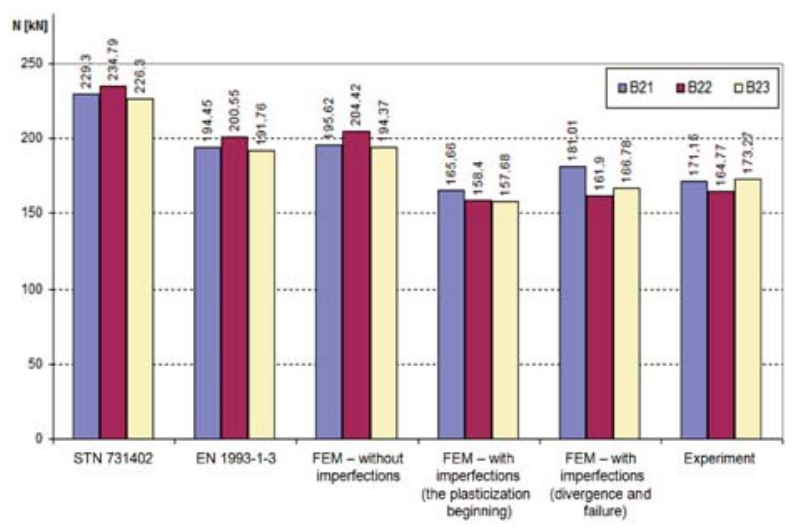

Fig. 6 Comparison of several limit loads; B21, B22 and B23

\section{Conclusion}

The resistances of the tested members, together with their postcritical behavior were investigated by means of theoretical-numerical analysis and experimental verification. Based on obtained experimental results, results acquired from the calculation models and analysis, it is evident that the resistances of the compressed thinwalled cold-formed steel members are significantly influenced by the initial imperfections and/or by the initial buckling shapes of their individual webs.

Fig. 6 indicates the results' conformity between the FEM simulation and theoretical calculation according to EN 1993-1-3:2006

- without considering the initial imperfections. This Figure also indicates the results' conformity between the FEM simulation and experiment results - with considering the initial imperfections. The difference in the results between the standard STN 73 1402:1998 and EN 1993-1-3:2006 is $14.58 \%$. The FEM simulation proves that the calculation procedures in the relevant standards are not sufficient enough for the consideration of the initial imperfections' influence.

In terms of tolerance values, the maximum measured imperfection of the webs was $1.51 \mathrm{~mm}$. This value is smaller than the maximum tolerated imperfection given in the standard EN 1090-2; A1:2012-03 as b/50, which is $4.15 \mathrm{~mm}$. Although the condition has been met, the results revealed a serious effect of initial imperfections.

Obtained results enlarge the knowledge base about the elasticplastic resistance of thin-walled cold-formed steel members, as well as about the influence of initial imperfections. Obtained knowledge and results encourage the more consistent analysis and research, oriented to limiting the tolerance values of initial imperfections for the thin-walled cold-formed profiles and members.

\section{Acknowledgements}

The present work has been carried out within the project ITMS 26220120037 "The Support to the Centre of Excellent Integrated Research into Progressive Building Structures, Materials and Technologies", based on the Operational program Research and development, financed by the European Regional Development Fund of the European Union.

\section{References}

[1] JUHAS, P. et al.: The Elastic-plastic behavior and Stress-strain Analysis of Framed and Flat Structural Members Made from Steel and Composite Materials. Research report VEGA 1/0673/10, Kosice, 2010-2011.

[2] AL ALI, M., TOMKO, M., DEMJAN, I., BADAK, M.: Stress-strain Analysis of Thin-walled Compressed Steel Members with Closed Cross-sections, SSP - J. of Civil Engineering 17/1, 2011, pp. 85-96.

[3] AL ALI, M., TOMKO, M., BADAK, M.: Investigation and Analysis of the Resistance of Compressed Cold-formed Steel Members. In: The Research of the Institute of Structural Engineering. Kosice, Slovakia 2010, pp. 13-18.

[4] STN 73 1402:1988 Design of Thin-walled Profiles in Steel Structures. UNM, Prague 1987.

[5] STN EN 1993-1-3:2006 Design of steel structures - Part 3: Supplementary Rules for Cold-formed Members and Sheeting. Brussels 2006.

[6] ANSYS Inc.: Theory, Release 9.0 [online]. Canonsburg: November 2004, 1062 p. <http://www1.ansys.com/customer/content/documentation/90/ansys/a_thry90.pdf>.

[7] ANSYS Inc.: Release 11.0 Documentation for ANSYS [online]. 2011. <http://www.kxcad.net/>.

[8] DANESHJO, N.: Computers Modeling and Simulation, Advanced Materials Research, 463/464, 2012, pp. 1102-1105. 